\title{
Qualidade da água do Rio Ribeirão das Pedras e a água tratada para consumo no Município de Mata Verde-MG: Uma Análise Comparativa dos Fatores Físicos-Químicos e Microbiológicos*
}

\author{
Carla Alves Gobira ${ }^{\text {; Stenio Fernando Pimentel Duarte }}{ }^{2}$
}

Resumo: A água é um recurso natural fundamental para o desenvolvimento econômica e uma matéria-prima indispensável para a produção de alimentos e geração de energia. No entanto, vale salientar que tanto quanto a agua é necessária à vida do ser humano, ela também pode veicular muitas doenças. A análise da qualidade água é feita a partir de parâmetros físico-químicos e microbiológicos que visam determinar qualidades e métodos de potabilidade da água para consumo humano. Tais parâmetros são constituídos por normas, padrões inclusos pela atual Portaria n ${ }^{\circ}$ 2.914/11 do Ministério da Saúde. O objetivo deste trabalho foi investigar a qualidade da água do Rio das Pedras, situado no munícipio de Mata Verde-MG e da água utilizada para consumo fornecida pela estação de tratamento da COPASA-MG para esta mesma população a fim de julgar se a água que abastece o munícipio atende os padrões de potabilidade ou se oferece riscos de doença à população. O estudo realizado foi do tipo quantitativo, qualitativo, de coorte e experimental, onde coletou-se uma amostra de água das torneiras de um bairro do município de Mata Verde-Mg e uma amostra do rio Ribeirão das Pedras que foram analisadas no laboratório NutriSegura ${ }^{\circledR}$ e o método utilizado nos ensaios foi o SMEWW-Standard Methods for the Examination of Water and Wastewater, 22nd. Edition, 2012. A análise e discussão dos dados foram realizados à luz da Portaria $n^{\circ}$ 2.914/11 e verificou-se que a água consumida pela população de Mata Verde- MG apresenta qualidade de potabilidade eficiente e dentro do que é preconizado pelo Ministério da Saúde.

Palavras- Chave: Água. Análise físico-químico. Análise Microbiológica. Qualidade. Saúde pública.

\section{Ribeirão das Pedras River Water Quality and Water Treated for Consumption in the Municipality of Mata Verde-MG: A Comparative Analysis of Physical-Chemical and Microbiological Factors}

\begin{abstract}
Water is a fundamental natural resource for economic development and an indispensable raw material for food production and energy generation. However, it is worth noting that as much as water is necessary to human life, it can also carry many diseases. The analysis of the water quality is made from physical-chemical and microbiological parameters that aim to determine qualities and methods of potability of the water for human consumption. These parameters are constituted by norms and standards included in the current Ministry of Health Ordinance No. 2,914 / 11. The objective of this study was to investigate the water quality of Rio das Pedras, located in the Municipality of Mata Verde-MG and water used for consumption provided by the treatment plant of COPASA-MG for this same population in order to judge if the water that supplies the municipality meets the standards of potability or offers disease risks to the population. The quantitative, qualitative, cohort and experimental study was carried out, where a sample of water from the taps of a district of the city of Mata Verde$\mathrm{Mg}$ and a sample of the river Ribeirão das Pedras were analyzed and analyzed in the NutriSegura ${ }^{\circledR}$ laboratory and the method used in the tests was SMEWW - Standard Methods for the Examination of Water and Wastewater, 22nd. Edition, 2012. The analysis and discussion of the data were performed in light of Ordinance No. 2,914 / 11 and it was verified that the water consumed by the population of Mata Verde-MG presents quality of efficient potability and within what is recommended by the Ministry of Health .
\end{abstract}

Key-Words: Water. Physical-chemical analysis. Microbiological analysis. Quality. Public health.

\footnotetext{
${ }^{1}$ Graduanda em Farmácia Generalista pela Faculdade Independente do Nordeste. Contato: carla.gobira@ outlook.com.

${ }^{2}$ Professor da Faculdade Independente do Nordeste.
} 


\section{Introdução}

Todas as atividades humanas se ligam ao consumo da água: seja pelo consumo direto, pela indústria, comércio, agricultura, enfim, todos os setores ligados ao abastecimento de produtos e serviços precisam de água para a manutenção de suas atividades. Ela é um recurso natural essencial para o desenvolvimento econômica e uma matéria-prima indispensável para a produção de alimentos e geração de energia (JACOBI; GRANDISOLI, 2017).

Os relatórios da Organização das Nações Unidas (ONU) sobre recursos hídricos enfatizam a importância da água para o progresso econômico e social dos países; nele constatase, por exemplo, que em algumas regiões o estado de seca tem ocasionado a anulação de safra de diversos produtos agrícolas, o que diminui a oferta de mantimentos e eleva o preço de venda no varejamento. Considerando que a agricultura é responsável por $70 \%$ da necessidade de água no mundo, o que sobra divide-se entre a produção de energia, a indústria e o consumo humano. Os relatórios acrescentam que a redução nos níveis de água diminuirá a produção agrícola e gerará crises de fornecimento de alimentos em todo o mundo, principalmente se ela se agravar por conta das mudanças climáticas (WWDR, 2014).

O abastecimento de água potável é um modo de julgamento das condições de vida das populações e está associado às demandas do crescimento populacional e as políticas governamentais criadas para garantir que o abastecimento seja realizado de modo igualitário às populações. Além de promover ações que procuram tratar e reaproveitar esgotos, promover saneamento básico e diminuir impactos ambientais gerados por problemas climáticos e de poluição (GONÇALVES et al., 2015).

No entanto, vale salientar que tanto quanto a agua é necessária à vida do ser humano, ela também pode veicular muitas doenças, tais como: amebíase, giardíase, gastroenterite, febre tifoide e paratifoide, hepatite e cólera. De acordo com publicação da revista Exame (2017) o consumo de água contaminada mata 3 milhões de pessoas por ano: onde acordo com relatório do Programa das Nações Unidas para o Meio Ambiente (PNUMA) 323 milhões de pessoas, mundialmente, correm o risco de pegar algumas dessas doenças devido a contaminação da água em diferentes regiões da América Latina, África e Ásia. Ainda segundo a mesma reportagem a presença de poluentes nas águas desses lugares, aumentou mais de 50\% e pelo menos 3,4 milhões de pessoas morrem por falta de tratamento adequado da água consumida. 
A análise da qualidade água é feita a partir de parâmetros físico-químicos e microbiológicos, aos quais estes determinarão qualidades e métodos para que a água tenha a característica ideal para uso quitado e consumo humano. Tais parâmetros são constituídos por normas regidas pela Portaria $n^{\circ}$ 2.914/11 do Ministério da Saúde que dispõe sobre os procedimentos de controle e de vigilância da qualidade da água para consumo humano e seu padrão de potabilidade.

Neste trabalho analisaremos coliformes totais, E-coli e Bactérias heterotróficas da água do rio que abastece a cidade de Mata Verde - MG; e a Turbidez, o PH e Cloro Residual Livre (CRL) da água tratada do mesmo munícipio.

A qualidade da água tem se tornado, desde o final do século XIX e início do século XX, objeto de estudo e uma questão de saúde pública. Atualmente, a Organização Mundial de Saúde - OMS que regulamenta, acompanha e recomenda a normatização da qualidade da água para consumo humano.

\footnotetext{
As normas de potabilidade têm se apresentado como um instrumento técnico-jurídico elaborado pelas autoridades sanitárias, com o apoio de instituições técnico-científicas, a ser cumprido pelos órgãos de fiscalização e vigilância do setor de saúde e pelas empresas públicas e privadas de abastecimento de água (FREITAS; FREITAS, 2005, p.996).
}

No entanto, a mera existência de normas regulamentadoras não assegura a certificação e a garantia de padrões de qualidade da água consumida pela população. Por isso, é fundamental que este assunto seja discutido e vigiado por toda a sociedade civil, incluindo gestores e acadêmicos a fim de assegurar maior legitimidade do direito à água potável. Diante do exposto este estudo teve como objetivo geral: investigar a qualidade da água do Rio das Pedras, situado no munícipio de Mata Verde-MG e da água utilizada para consumo fornecida pela estação de tratamento da COPASA-MG para esta mesma população; e como objetivos específicos: analisar físico-química e bacteriologicamente de acordo com os padrões adotados Portaria $\mathrm{n}^{\mathrm{o}}$ 2.914/11 do Ministério da Saúde e a partir desses resultados julgar se a água que abastece o munícipio atende os padrões de potabilidade ou se oferece riscos de doença à população. 


\section{Metodologia}

\section{Área de Estudo: Amostragem}

Trata-se de uma pesquisa experimental realizada no município de Mata Verde, no estado de Minas Gerais, Brasil. O município se estende por $227,5 \mathrm{~km}^{2}$ e conta, segundo dados do último censo, com 7.874 habitantes. A densidade demográfica é de 34,6 habitantes por $\mathrm{km}^{2}$ no território da cidade. Estimou-se que em 2017, a população de Mata Verde-MG estivesse em 8.539 pessoas (IBGE, 2017). A Figura 1 mostra um mapa da região estudada.

Figura 1. Mapa da localização de Mata Verde em Minas Gerais.

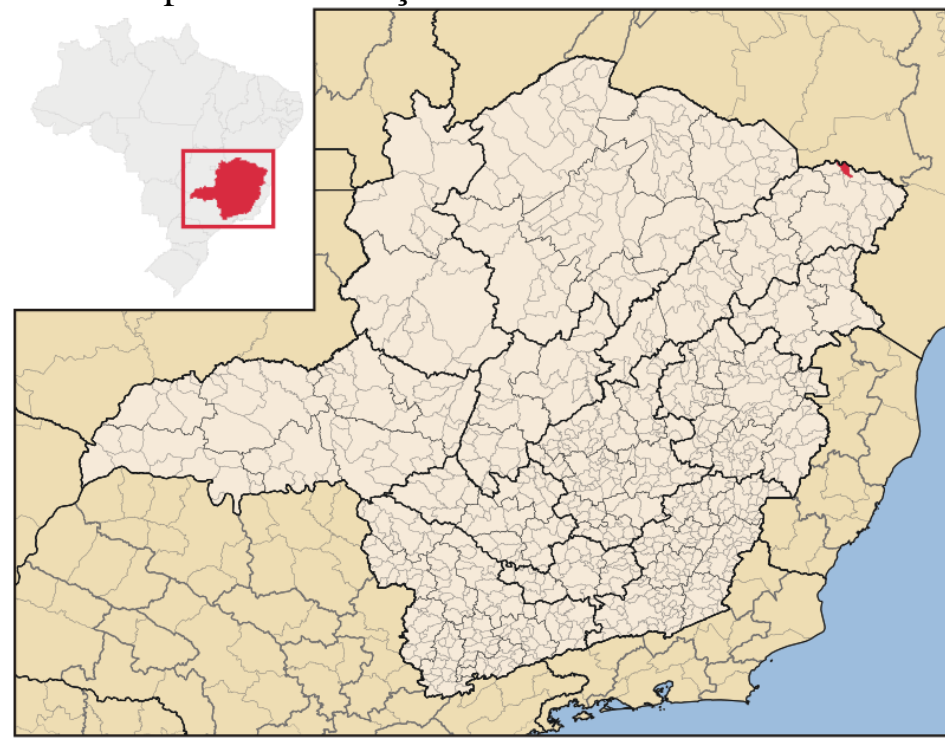

Fonte: Disponível em:https://pt.wikipedia.org/wiki/Mata_Verde\#/media/File: MinasGerais_Municip_MataVerde.svg. Acesso em Abril de 2018.

Segundo IBGE (2017) neste município 71.9\% de domicílios possuem esgotamento sanitário adequado e 39.2\% de domicílios urbanos em vias públicas com urbanização adequada, ou seja, com presença de calçada, bueiro, meio-fio e pavimentação.

O fornecimento de água é feito pela Companhia de Saneamento de Minas Gerais COPASA-MG, empresa de economia mista que apresenta como principal atividade a prestação de serviços em abastecimento de água, esgotamento sanitário e resíduos sólidos. Ela atua nas 12 mesorregiões do Estado de Minas Gerais e atende 635 dos 853 municípios com o trabalho 
de abastecimento de água, dos quais se enquadra a cidade de Mata Verde-MG, pertencente ao Vale do Jequitinhonha, no nordeste do estado.

A bacia do rio Ribeirão das Pedras localiza-se na divisa da Bahia com Minas gerais. É um divisor de água dos dois estados, parte das nascentes deste divisor, forma o rio das pedras e desagua na bacia do rio Pardo, parte forma o rio Panela e o córrego Veados, que desagua na bacia do rio Jequitinhonha. O rio Ribeirão das Pedras tem contribuição na sua formação de 12 nascentes, toda área da bacia é coberta por lavoura de café.

\section{Tipo de Estudo}

Este estudo é do tipo quantitativo, qualitativo, de coorte e experimental. Foi coletada uma amostra de água das torneiras de um bairro do município de Mata Verde-Mg e uma amostra do rio Ribeirão das Pedras.

Todo o plano de trabalho de coleta foi realizado com base no Manual de procedimentos de amostragem e análise físico-química de água para que toda amostra fosse manuseada de tal modo que nenhuma mudança significativa na sua composição aconteça antes da análise realizada. A seguir, listamos as recomendações seguidas nesta coleta: primeiramente, certificamos que todos os materiais estivessem limpos e livres de contaminantes; foram coletadas nas torneiras após deixar a água escorrer por três minutos; e, imediatamente, após a coleta identificamos e acondicionamos a amostra em caixa térmica, com bolsas térmicas gel, até a chegada ao laboratório (PARRON et al., 2011)

\section{Coleta e Análise da Água}

As amostras foram coletadas em dois pontos específicos: o primeiro ponto de coleta foi no rio Ribeirão das Pedras, o lugar de coleta foi nas proximidades de canalização para tratamento. A segunda amostra foi coletada em um ponto residencial do centro da cidade, em uma torneira com água diretamente da COPASA sem passar por nenhum tipo de reservatório. Nessa coleta, realizou-se a higienização da torneira antes da coleta, utilizando álcool $70^{\circ}$ ou solução de hipoclorito de sódio de $100 \mathrm{mg} / \mathrm{L}$. Enxaguou-se bem a torneira após o procedimento, 
deixou escoar a água em vazão alta por cerca de 3 minutos, a fim de que fosse eliminado os possíveis resíduos do desinfetante utilizado e a água estagnada na tubulação.

Ambas coletas foram realizadas em frascos lacrados, de polietileno com capacidade para $1000 \mathrm{ml}$ e um frasco de vidro estéril com capacidade de $250 \mathrm{ml}$. Esses compartimentos foram fornecidos pela empresa Nutri Segura, situado em Vitória da Conquista-BA, laboratório particular que presta serviços em análises físico-química e microbiológicas em alimentos e água e realizou a análise deste trabalho.

As amostras foram coletadas no período da tarde entre 15:30 e 16:20 aproximadamente, do dia 08/05/2018, o dia estava ensolarado com algumas nuvens, a máxima prevista era de $21^{\circ} \mathrm{C}$ e a mínima prevista de $18^{\circ} \mathrm{C}$, colocadas em um isopor térmico e logo em seguida foram encaminhados a laboratório de análise.

As análises físico-químicas e microbiológicas foram realizadas no laboratório NutriSegura ${ }^{\circledR}$ e o método utilizado nos ensaios foi o SMEWW - Standard Methods for the Examination of Water and Wastewater, 22nd. Edition, 2012. No dia 09 de Maio do presente ano as amostras foram retiradas da refrigeração, acondicionadas em um isopor contendo gelo reciclável e levadas para o laboratório supracitado, para serem submetidas aos ensaios e nesse e no dia 10 deu-se o término e resultado das análises realizadas.

\section{Resultados e Discussão}

De acordo com regulamentação do Ministério da Saúde a água potável não pode conter bactérias patogênicas e deve permanecer livre de micro-organismos indicadores de contágio fecal. Os identificadores de infecção fecal pertencem a um grupo de bactérias denominadas coliformes. O principal representante desse grupo de bactérias chama-se Escherichia coli (BRASIL, 2006). Por isso, o exame microbiológico da água objetiva fornecer subsídio a respeito potabilidade da água, ou seja, verificar se há risco de ingestão de micro-organismos causadores de doenças, na maioria das vezes originárias da contaminação pelas fezes humanas e outros animais de sangue quente (BRASIL, 2013).

A mais recente Portaria da Potabilidade, n 2.914/2011 do Ministério da Saúde, preconiza que seja verificada este exame na água para consumo humano a fim de garantir sua 
qualidade, a ausência de coliformes totais e Escherichia coli e determinada a contagem de bactérias heterotróficas.

$\mathrm{Na}$ análise do padrão microbiológico de potabilidade é imprescindível a ausência de coliformes totais em $100 \mathrm{~mL}$ de amostra na saída do tratamento, como também não se deve apresentar a Escherichia coli na água para consumo humano. A Contagem Padrão de Bactérias é muito importante durante o processo de tratamento da água, visto que permite avaliar a eficiência das várias etapas do tratamento. Com relação a bactéria heterotrófica preconiza-se que não ultrapasse o limite de $500 \mathrm{UFC} / \mathrm{mL}$ em amostras de água; estas bactérias são aquelas utilizadas como matéria orgânica como fonte de carbono e podem apresentar-se em diversos ambientes, como água, solo, alimentos e ar (BRASIL, 2013).

Com relação a análise microbiológica realizada com a água bruta e água tratada no munícipio de Mata Verde - MG, os resultados obtidos demonstram, conforme se vê na Tabela 1, que a apresentaram contagem de bactérias heterotróficas estão de acordo com os recomendados pela legislação vigente, tanto na água bruta, quanto na água tratada. Assim, tendo em vista que a água do Rio das Pedras possui um baixo nível de bactérias heterotróficas, isso mostra a eficiência nos processos de manutenção, higienização de equipamentos e sistemas de captação de águas minerais em suas fontes pela empresa responsável pelo tratamento e favorece a população na medida que não os transmite doenças hídricas. Vale ressaltar o baixo valor encontrado determinação da densidade de bactérias heterotróficas favorecem a detecção de bactérias do grupo coliformes; quando o limite dessas bactérias é ultrapassado podem comprometer a detecção de bactérias do grupo coliformes e apresentam riscos à saúde, como também faz com que a qualidade da água seja comprometida provocando nela odores e sabores desagradáveis.

Quanto a presença dos Coliformes totais e E-coli, a Tabela 1 mostra que na água bruta há presença desses micro-organismos, no entanto na água tratada para consumo da população isso não acontece. Logo, a água consumida por esta população é uma com qualidade de potabilidade eficiente e dentro do que é preconizado pelo Ministério da Saúde. 
Tabela 1. Resultado da análise microbiológica realizada com água bruta e água tratada do munícipio de Mata Verde - MG.

\begin{tabular}{|c|c|c|c|}
\hline & $\begin{array}{c}\text { Água Bruta } \\
11^{\circ} \mathrm{c}\end{array}$ & $\begin{array}{c}\text { Água Tratada } \\
10,4^{\circ} \mathrm{c}\end{array}$ & $\begin{array}{c}\text { Parâmetros de } \\
\text { Qualidade }\end{array}$ \\
\hline Coliformes totais & Presente & Ausente & Ausente \\
\hline Escherichia coli & Presente & Ausente & Ausente \\
\hline $\begin{array}{c}\text { Bactérias } \\
\text { Heterotróficas }\end{array}$ & 137 & 5 & $500 \mathrm{UFC} / \mathrm{mL}$ \\
\hline
\end{tabular}

Fonte: Nutri Segura, Vitória da Conquista - BA, 2018.

Assim como as propriedades microbiológicas da água é importante que as propriedades físico-químicas não se encontrem alteradas, pois quando isso ocorre configura-se um quadro de risco para a população.

O PH (Potencial Hidrogeniônico) é a classificação de uma substância em relação a sua concentração de íons $\mathrm{H}+$, desta forma identifica o exercício do hidrogênio no meio. O valor do pH varia de 0 a 14: quando esse valor dá abaixo de 7 a água é considerada ácida; acima de 7 , alcalina; e com pH 7 é neutra. Recomenda-se que o pH da água seja mantido na faixa de 6,0 a 9,5 no sistema de distribuição (BRASIL, 2013).

A análise da turbidez da água é importante para verificar a presença de materiais sólidos em suspensão, que abreviam a sua limpidez e é provocada pela presença de algas, plâncton, matéria orgânica e outras substâncias como a areia, o zinco, o manganês e o ferro, gerado por erosão ou escoamentos de dejetos domésticos e industriais. Essa análise é importante no processo de tratamento da água, pois quando ela está com valores elevados dependendo de sua natureza forma blocos pesados que decantam mais ligeiramente do que água com baixa turbidez. É o padrão organoléptico e um indicador sanitário da água para o consumo humano. A atual norma de potabilidade da água aciona organizações internacionais relacionadas à transmissão de micro-organismos por abastecimento de água e quanto a turbidez, o valor máximo permitido é de 0,5 e 1,0 UT para água subterrânea pós-filtração e 5,0 UT em qualquer ponto da rede de distribuição (BRASIL, 2013).

O cloro, por sua vez, é um produto químico utilizado no tratamento da água. Sua medida é importante, pois controla a dosagem aplicada e também acompanha a evolução durante o tratamento. A Portaria do Ministério da Saúde não institui a concentração mínima de cloro para a saída do tratamento, no entanto determina a obrigatoriedade de se manter, no mínimo, 0,2 mg/L de cloro residual livre em toda a extensão do sistema de distribuição 
(reservatório e rede) e adverte que o teor máximo de cloro residual livre seja de $2 \mathrm{mg} / \mathrm{L}$ em qualquer ponto do sistema de abastecimento; não é expressado a concentração mínima de cloro para a saída do tratamento (BRASIL, 2013).

Os resultados obtidos na análise físico-química da água bruta e da água tratada pela estação de tratamento do município mostram, conforme apresentado na Tabela 2, que a água bruta possui PH ácido e a água tratada alcalina, no entanto ambas se encontram com valores dentro da normalidade permitida por lei. No tocante a turbidez, considerando como valor máximo de referência, 5,0 UT, que é o permitido em outras redes de distribuição tais como as estações de tratamento e águas de torneira, vê-se, também, que a água bruta e água já tratada também se encontram dentro da normalidade, sendo que na água tratada a presença de turbidez está bem abaixo, o que indica a qualidade da água consumida por esta população. Por fim, a análise do Cloro Residual Livre, foi o único resultado que apresentou alterações no que se refere a água bruta, pois o valor mínimo exigido pela regulamentação é $0,2 \mathrm{mg} / \mathrm{L}$ em toda a extensão do sistema de distribuição, incluindo o reservatório e a rede de tratamento. Neste sentido, vê-se a necessidade de que os laboratórios das estações de tratamento meçam e ajustem essa oferta a fim de melhorar o processo de coagulação da água e também o controle da desinfecção.

Tabela 2. Resultado da análise físico-química realizada com água bruta e água tratada do munícipio de Mata Verde - MG comparado aos parâmetros determinados pela Legislação.

\begin{tabular}{|c|c|c|c|}
\hline 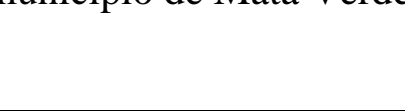 & $\begin{array}{c}\text { Água Bruta } \\
11^{\circ} \mathrm{c}\end{array}$ & $\begin{array}{c}\text { Água Tratada } \\
10,4^{\circ} \mathrm{c}\end{array}$ & Parâmetros \\
\hline PH & 6,08 & 8,2 & $6,0-8,0$ \\
\hline Turbidez & 3,17 & 0,39 & $\begin{array}{c}0,5 \text { e } 1,0 \text { UT para } \\
\text { água subterrânea } \\
5,0 \text { UT em outras } \\
\text { redes de } \\
\text { distribuição }\end{array}$ \\
\hline Cloro Residual Livre & 0,14 & 1,10 & $\begin{array}{c}\leq 0,2 \mathrm{mg} / \mathrm{L} \mathrm{e} \geq 2 \\
\mathrm{mg} / \mathrm{L}\end{array}$ \\
\hline
\end{tabular}

Fonte: Nutri Segura, Vitória da Conquista - BA, 2018.

\section{Considerações Finais}

O presente estudo teve como objetivo investigar a qualidade da água do Rio das Pedras, situado no munícipio de Mata Verde-MG, e da água utilizada para consumo fornecida pela 
estação de tratamento da COPASA-MG para esta mesma população a partir de exames físicoquímico e bacteriologicamente determinados pelos padrões adotados Portaria $\mathrm{n}^{\circ}$ 2.914/11 do e a partir desses resultados julgar se a água que abastece o munícipio atende os padrões de potabilidade ou se oferece riscos de doença à população.

Com isso, o resultado da análise microbiológica mostrou que a contagem de bactérias heterotróficas está de acordo com os recomendados pela legislação vigente, tanto na água bruta, quanto na água tratada. Quanto a presença dos Coliformes totais e E-coli viu-se que na água bruta há presença desses micro-organismos, no entanto na água tratada para consumo da população isso não acontece. Na análise físico-química os resultados mostram ambas amostram encontram valores de $\mathrm{PH}$ e Turbidez dentro da normalidade permitida por lei. No entanto, a análise do Cloro Residual Livre foi o único resultado alterado no que se refere a água bruta, pois o valor mínimo exigido pela regulamentação é $0,2 \mathrm{mg} / \mathrm{L}$ em toda a extensão do sistema de distribuição, incluindo o reservatório e a rede de tratamento. Por isso, discutiu-se a necessidade de que os laboratórios das estações de tratamento meçam e ajustem essa oferta a fim de melhorar o processo de coagulação da água e também o controle da desinfecção. Mas no que se refere a água que chega às casas da população, o valor de CRL encontra-se dentro da normalidade.

Assim, julga-se que a água consumida pela população de Mata Verde- MG apresenta qualidade de potabilidade eficiente e dentro do que é preconizado pelo Ministério da Saúde.

\section{Referências}

BRASIL. Fundação Nacional de Saúde. Manual prático de análise de água / Fundação Nacional de Saúde - 4. ed. - Brasília : Funasa, 2013.

CIDADE-BRASIL. Mata Verde. 2016. Disponível em: http://www.cidadebrasil.com.br/municipio-mata-verde.html. Acesso em Abril de 2018.

JACOBI, P.R. GRANDISOLI, E. Água e sustentabilidade: desafios, perspectivas e soluções. São Paulo: IEE-USP e Reconectta, 2017. $1^{\text {a }}$ Edição.

GONÇALVES, K. O.; FERNANDES, L.L.; GIRARD, L. Diagnóstico do serviço de abastecimento de água na percepção do usuário no munícipio de Barcarena - Pará. Revista Monografias Ambientais - REMOA, v.14, n.1, Jan-Abr, 2015. 
IBGE - Instituto Brasileiro de Geografia e Estátistica. Brasil, Minas Gerais, Mata Verde, 2017. Disponível em: https://cidades.ibge.gov.br/brasil/mg/mata-verde/panorama Acesso em Abril de 2018.

PARRON, L.M.; MUNIZ, D.H.F.; PEREIRA, C.M. Manual de procedimentos de amostragem de análise físico-química de água. Embrapa Florestas, Colombo-PR, 2011.

SILVA et al. Análise Físico-Química e Microbiológica da Água Tratada do Município de Córrego de Ouro. Revista Faculdade Monte Belos (FMB), v.8, nº 1, 2015.

WORLD WEALTH REPORT (WWR). Capgemini and RBC Wealth Management. Canadá, 2014. Disponível em http://pbwm.ru/library/ world-wealth-report-2014/download. Acesso em Maio de 2018.

\section{Como citar este artigo (Formato ABNT):}

GOBIRA, Carla Alves; DUARTE, Stenio Fernando P. Qualidade da Água do Rio Ribeirão das Pedras e a Água Tratada para Consumo no Município de Mata Verde-MG: Uma Análise Comparativa dos Fatores Físicos-Químicos e Microbiológicos. Id on Line Revista Multidisciplinar e de Psicologia, 2018, vol.12, n.40, p.1082-1092. ISSN: 1981-1179.

Recebido: 28.05.2018

Aceito: 29.05 .2018 